\title{
DE ÉLISABETH GILLE A IRÈNE NÉMIROVSKY: RECREACIÓN DE UN DOBLE ITINERARIO DE VIDAA TRAVÉS DE LA ESCRITURA
}

\author{
FROM ELISABETH GILLE TO IRÈNE NÉMIROVSKY: A DOUBLE \\ ITINERARY OF LIFE RECREATED THROUGH SCRIPTURE
}

\author{
M. Carme FIGUEROLA CABROL \\ Universitat de Lleida \\ cfiguerola@filcef.udl.cat
}

\begin{abstract}
Resumen: Los dramáticos acontecimientos de la Segunda Guerra Mundial privaron de la presencia materna a Élisabeth Gille. Esa niña a quien le fue imposible dar sepultura a su madre se pone en su piel en Le Mirador. En un proceso memorial el relato narra la infancia de la propia hija, sus experiencias durante la guerra y la posguerra, a la vez que esboza el recorrido vital de esa madre casi desconocida adoptando distintos mecanismos narrativos para cada una. Los singulares pasajes referidos a Gille constituyen un eco de la existencia de Némirovsky. El objetivo de este análisis consiste en observar cómo una escritora da voz a la otra para desvelar al lector sus experiencias y el sufrimiento de ambas ante la tragedia que las marcó con una huella indeleble.
\end{abstract}

Palabras clave: E. Gille. Autoficción. Identidad.

Abstract: The dramatic events of World War II deprived Elisabeth Gille of the maternal presence. That girl who was unable to bury her mother puts herself her skin in Le Mirador. In a memorial process, the story narrates the 
daughter's own childhood, her experiences during the war and the postwar period, while she outlines the life path of this almost unknown mother by the adoption of different narrative mechanisms for each one. The singular passages referred to Gille constitute an echo to Némirovsky's existence. This analysis aims to observe how a writer gives voice to the other one to reveal to the reader their experiences and the suffering of both during the tragedy that marked them with an indelible fingerprint.

Key Words: E. Gille. Autofiction. Identity.

En la escritura autobiográfica del siglo XX la construcción de la identidad femenina ha tenido como una de sus constantes el análisis de las relaciones entre madre e hija, a menudo conflictivas o al menos determinantes en el progreso psicológico de las escritoras. Así lo confirman diversos estudios (Morello \& Rodgers, 2002: 23; Rye, 2009: 155) que muestran cómo el relato calificado de autoficción convierte a las progenitoras en objeto del discurso sobre el que las narradoras vuelcan sus frustraciones, sus temores y, en definitiva, sus propios traumas. Élisabeth Gille constituye uno de los ejemplos que coinciden con dicha práctica. El interés de su caso emana además de la excepcionalidad de su trayectoria vital. Por ser hija de Irène Némirovsky, Gille asume el drama que marcó de forma indeleble la vida de su madre. Tras experimentar un exitoso devenir literario, Némirovsky pasó al purgatorio mayormente por el trágico desenlace sufrido durante el holocausto. Con su muerte en Auschwitz se instaló un silencio que sólo se diluyó en pleno siglo XXI, momento de la publicación de su obra póstuma Suite française. Premiada con el Prix Renaudot la convierte en ave fénix, catapultándola de nuevo a la primera fila de las letras francesas.

Por su parte, también Élisabeth experimentó en su propia carne los estragos de la Segunda Guerra Mundial. Unos meses después de la deportación de Irène, su padre sufría la misma suerte y la pequeña, con tan solo cinco años, quedaba junto a su hermana mayor a cargo de su cuidadora Julie Dumot. Empezaba entonces un penoso peregrinaje para escapar de las patrullas alemanas: la primera etapa de su clandestinidad transcurre en un internado católico donde las monjas recurrían a peripecias varias 
para camuflar sus orígenes judíos ${ }^{1}$. Tras el fin de las hostilidades y ante la negativa de su abuela a hacerse cargo de las pequeñas, ambas hermanas sobrevivieron gracias a las pensiones recibidas de editores como Albin Michel que restituían de ese modo los derechos de autoría de su madre. Con posterioridad Élisabeth fue acogida por la familia Avot que había trabado una fuerte amistad con Irène Némirovsky. Ya en su edad adulta convirtió la literatura en su profesión puesto que ejerció como editora para empresas de la talla de Denoël, Flammarion y Julliard donde su actividad corría pareja a la de escritores de prestigio (Françoise Sagan, Juliette Benzoni, Emmanuel Carrère, Lydie Salvayre...). Asimismo se consagró a la traducción al francés de autores como Kate Millett, Peter Taylor, Alison Lurie, James Graham Ballard o Patricia Highsmith, entre otros.

Ya en la recta final de su vida Gille abordó la literatura desde otra perspectiva, la de autora. Tres obras de muy distinto calado forman el corpus de la escritora: Le Mirador, donde recurre a la primera persona para narrar la existencia de su madre y la suya; Le Crabe sur la banquette arrière, obra de teatro cuyo motivo central es la enfermedad que ella misma sufría -el cáncer- y que no tardará en acabar con sus días. Le sigue por último Un paysage de cendres, novela donde recrea la infancia y adolescencia de una protagonista muy parecida a ella. Aunque somera presentación, lo apuntado permite adivinar ya la importancia que cobra el factor autobiográfico en la ficción de Gille.

El presente análisis tiene como objeto demostrar cómo en Le Mirador, esa niña a quien le fue imposible dar sepultura a su madre se pone en su piel. La autoficción permite a Élisabeth Gille imaginar los sentimientos que Némirovsky, esa madre casi desconocida, debió experimentar en su día. A la par que efectúa un proceso memorial, el relato se estructura en un doble registro que narra la infancia de la propia hija, sus experiencias durante la guerra y la posguerra. Una escritora da voz a la otra para develar ante el lector sus inquietudes comunes pese al trecho que las separa.

El reto que Élisabeth Gille se marca al pretender trazar dicha síntesis no es ínfimo puesto que página a página debe superar una serie de circunstancias complejas: en su perspectiva más íntima ¿cómo reconstruir de forma verosímil la vida de la madre perdida a la edad de cinco años?,

1. Gille se inspira de esa vivencia y la reinterpreta en su novela Un paysage de cendres (1996). 
¿cómo sortear la ausencia de familiares directos ${ }^{2}$ para suplir una frágil memoria? En virtud de esa distancia temporal, ¿cómo combatir algunos de los estereotipos que evocaba la identidad de Némirovsky: su procedencia rusa, su judaísmo...? La misma autora reconocía que ese fue uno de los mayores escollos: 'Le problème, c'est que de 1903 à 1930 je n'avais aucun document sur elle" (Gille, 2000: 417). A nivel profesional, siendo ella misma descubridora de algunos escritores contemporáneos, ¿cómo rendir homenaje sin caer en el elogio fácil a la que en su día algunos igualaron a Balzac, a Dickens, a Dostoievsky o a Zola (Philipponnat \& Lienhardt, 2007: 175-176)? A lo anterior se añade la triste coincidencia de que cuando Gille escribe Le Mirador se sabe ya aquejada de una enfermedad sin remedio: la muerte se convierte, pues, en uno de los temas cruciales de la obra, palpable en cada página. Sin embargo, la literatura permite a Gille "engendrar" a su madre, ofrecerle una existencia acaso más sólida que la física. Además, el relato constituye un espejo en el que la propia Gille fija su imagen pública y privada puesto que actúa asimismo como un laboratorio de escritura.

Esa confluencia de intereses se resuelve con un doble entramado narrativo al que la autora opta por dar una clara visibilidad: el discurso biográfico se elabora mediante la primera persona para dar paso a la reconstrucción de la vida de Irène Némirovsky. Gille se eclipsa tras la voz de su madre para rememorar la infancia de ésta, su adolescencia, los prolegómenos de la Segunda Guerra para concluir con su deportación. Como es lógico, la narradora se ve obligada a obturar su mirada sobre el conflicto bélico. Rehuyendo la solución manida del genocidio, Gille prefiere centrarse en hasta qué punto la guerra supuso para su madre, ergo para ella, una concienciación de su alteridad. Mientras que para Némirovsky el judaísmo vivido como un respeto a tradiciones seculares ${ }^{3}$ se convirtió en barrera insuperable e impuso una nueva lectura de los acontecimientos, a Gille la perspectiva cronológica le permite esquivar los imponentes silencios de la posguerra. Se posiciona a favor de un deseo de saber compartido con muchos descendientes de deportados que constituyen

2. Su padre Michel Epstein y la hermana de éste murieron en Auschwitz en 1942. Hasta su mismo fallecimiento la abuela materna, Fanny Némirovsky, rechazó cualquier tipo de contacto con las nietas. Su tía materna murió en Moscú en 1988. En cuanto a su hermana mayor, una cierta distancia emocional las separa puesto que como señala esta última: "Nous n'avions pratiquement pas le même passé, car nous avons été séparées très vite, dès après la guerre, en fait" (Corpet, 2010: 40).

3. La misma Gille reconoce la falta de religiosidad en la madre, mostrándose incluso perpleja respecto a su conversión al catolicismo: “Je ne sais pas pourquoi elle s'est fait baptiser, alors qu'il n'y a aucune trace de foi religieuse dans son œuvre ni dans ses lettres" (Gille, 2000: 419). 
ya la segunda generación (Bornand, 2004: 28). Por añadidura, el propósito de Gille de rescatar del olvido el caso materno, fin que podría reducirse a un empeño individual, cobra una mayor trascendencia por la ejemplaridad que persigue: 'J'ai voulu, en écrivant la biographie de quelqu'un qui a fini aussi tragiquement, que mon livre serve, même modestement à une prise de conscience" (Gille, 2000: 422).

A partir de tal presupuesto todas las connotaciones del texto adquieren importancia, empezando por el título: la utilización del término Mirador evoca la metáfora un tanto stendhaliana de la literatura como espejo. Némirovsky centra gran parte de su atención. Sin embargo, Gille rehúye una foto estática. En su lugar asistimos a la formación de una personalidad con particular atención a los factores psicosociológicos que explican su evolución. Así se justifica la polifonía de ópticas a las que recurre para reconstituir los episodios vividos.

Por otra parte el subtítulo elegido alude al género de la obra de una forma cuando menos paradójica: Mémoires rêvés sitúa al receptor en el ámbito de la literatura autobiográfica. La introspección inherente a ese tipo de texto conlleva una ordenación de los acontecimientos pasados. En las memorias los recuerdos se entrelazan con la particularidad, según Lejeune (1975: 14) o Didier (1976: 20), de sobrepasar el ámbito individual para referirse a un colectivo social que comparte esa misma época. Al referirse a su vida en primera persona, la narradora se aproxima al testimonio, lo cual añade a la obra una connotación ética (Bornand, 2004: 28) mucho más sensible por el hecho de referirse al holocausto. Puesto que el lector concede mayor o menor validez a lo narrado en función de la credibilidad del narrador, Gille -consciente del obstáculo que podía suponer su condición de hija de la escritora- opta por añadir a la trayectoria íntima de Némirovsky el análisis de un trasfondo histórico ${ }^{4}$. Compensa de este modo la cortedad de detalles sobre determinadas etapas de la existencia materna, según reconoce ella misma:

Je venais de lire un document sur un pogrome qui avait atteint les quartiers riches de Kiev. À partir du Kiev de Boulgakov et des Mémoires de Constantin Paoustovski, j'ai

4. Al entrelazar lo individual y lo colectivo Gille retoma una tradición de la escritura autobiográfica tal y como la interpretó Simone de Beauvoir quien se caracterizó por combinar su experiencia propia con la de sus contemporáneos. 
tenté d'imaginer la vie d'une fillette confrontée à l'Histoire au début du siècle (Gille, 2000: 417).

Dicha decisión le lleva a revisar episodios cruciales para comprender la época: las masacres contra los judíos acaecidas en Kiev y Odesa en 1905, el declive de la Rusia zarista y la violenta toma del poder por las fuerzas revolucionarias bolcheviques, el rutinario exilio de algunos rusos, la despreocupación reinante en la Belle Époque, el estallido de la Primera Guerra Mundial... Por otra parte, si bien es cierto que Gille narra varios episodios familiares de Irène, se concentra en su vida pública, examina su eclosión como escritora, su progreso en el mundo de las letras o su posicionamiento acerca de temas controvertidos como la guerra, el racismo o la muerte. Al lector familiarizado con las tesis de Némirovsky le resulta fácil entrever en el volumen de la hija los temas tratados por la madre que Gille evoca en un doble procedimiento: ya sea sintetizando la esencia de una obra para subrayar su influencia en el desarrollo de sus principios intelectuales y morales, como sucede con David Golder:

Quant aux riches Israélites, je ne sais pas comment réagiront mes parents et leurs amis s'ils lisent un jour le roman que je viens de terminer. Il s'appelle David Golder, du nom du personnage principal, et je n'y ménage pas ce milieu (Gille, 2000: 70).

En otros pasajes Gille crea situaciones en que Irène se enfrenta a motivos que ella misma había tratado en sus novelas. Procedimiento comprensible puesto que Némirovsky trasladó muchas de sus vivencias sirviéndose de la fantasía para superar sus dramas personales ${ }^{5}$. Son varias las escenas donde la aún niña se rebela contra la autoridad materna:

Ce voyage fut l'occasion de mon premier caprice. Je me mis en tête qu'il me fallait à tout prix un costume marin. Ma mère, si prodigue pour ses propres toilettes, n'en voyait pas la nécessité. Elle tenait à m'affubler d'une immonde robe

5. En concreto las desavenencias con su madre nutren especialmente Le Bal o Jézabel hasta el punto de que uno de sus biógrafos afirma: “Jézabel solde une fois pour toutes les comptes d'Irène Némirovsky et de Fanny devant le jury des lecteurs” (Philipponnat \& Lienhardt, 2007: 270). 
écossaise accompagnée d'une cape en lin et un manchon (Gille, 2000: 40).

Dicho fragmento recuerda fácilmente a la protagonista de Le Bal, sin olvidar que entre las imágenes de la propia autora que se conservan figura un par de fotografías donde la niña posa junto a su madre con dicha vestimenta (Corpet, 2010: 61). En el mismo sentido se orienta la recreación de una fiesta en honor a la mayoría de edad de la protagonista que Gille recupera (Gille, 2000: 264) y que constituye el núcleo esencial de Le Bal. En esa senda figura la negativa de la joven embarazada que rechaza el aborto a pesar de las insistentes presiones de su madre (Gille, 2000: 108), en un claro intertexto de Jézabel; asimismo su concepción del judaísmo como un legado de tradiciones ancestrales recupera la postura que Némirovsky manifestó en Le maître des âmes.

En contrapartida el espacio dedicado a Gille representa un breve porcentaje del discurso en Le Mirador y no obstante, cobra un interés plausible desde el subtítulo: al añadir el adjetivo "rêvés" Gille admite desde el principio que no todo lo narrado ha sido vivido en su integridad. Pero además "revés" conduce al lector a compartir la visión de Bachelard para quien el proceso onírico es un potente motor de la creación literaria puesto que el pensamiento actúa con absoluta libertad (Bachelard, 1960). La ensoñación supliría la ausencia de episodios vividos en carne y hueso, amortiguaría las dudas y vacilaciones, los silencios o los vacíos que desgastan el recuerdo. Se establece con ello un diálogo sin rupturas entre la realidad histórica y la ficción: si la primera le permite convocar ciertos hechos, la segunda le brinda un espacio donde es posible trascribir el sentimiento individual, la pesadumbre de Némirovsky frente a la barbarie y la propia perplejidad de Gille ante la conducta de su madre. Gracias a la ficción la hija logra resolver el dilema que desde un tiempo atrás venía acechándola y al cual se refiere explícitamente:

Dans mon adolescence, je lui en voulais de son inconscience politique. Elle ne s'était pas sauvée, alors qu'elle avait toutes les possibilités de le faire et elle nous avait mises, ma sœur et moi, en danger. Nous avons été arrêtées et nous aurions dî, en toute logique, finir comme elle et comme mon père, à Auschwitz. Son aveuglement était criminel 
(Gille, 2000: 417).

Para sugerir lo paradójico de su situación la autora recurre desde el mismo incipit a las tesis de Georges Perec a quien cita aunque sin aportar la referencia concreta ${ }^{6}$. Varias circunstancias denotan una considerable afinidad entre ambos: su alusión común a los pogromos nazis o la repercusión negativa que para ellos supuso la Segunda Guerra Mundial. Desde el punto de vista narratológico comparten el estatuto de testigos cuyos relatos distan de ser usuales. Se alejan de lo esperable de su condición ya que sus discursos se compensan con la imaginación sin que se sientan obligados a justificar lo narrado. Los recuerdos son casi inexistentes y el texto se convierte en un puente entre lo que realmente fue y lo que se evoca para implicar al lector y que él mismo se convierta en testigo de las consecuencias provocadas por la guerra. La fragilidad de la memoria y la muerte conllevan para ambos el origen de la creación artística, una resurrección frente a los acontecimientos examinados: “...l'écriture est le souvenir de leur mort et l'affirmation de ma vie" (Gille, 2000: 30). Mediante estos términos también recuperados de Perec la hija alumbra a la madre en un movimiento recíproco al que Némirovsky efectuó al dar a luz a Gille... Lejos de representar una simple metáfora, la imagen adquiere su envergadura por el hecho de que en ese mismo pasaje Gille describe su nacimiento en 1937. Por analogía, la llegada al mundo se asimila al descubrimiento de la luz que la escritura proporciona a Gille. Además de Perec, Gille recurre a Valéry para reforzar el aspecto memorial: a modo de intertexto escoge dos versos de La Jeune Parque, poemario escrito durante la Gran Guerra, donde la figura de la Parca reivindica el poder de la memoria y a la conciencia (Tallandier, 2008: 179).

En su conjunto el proceso de substitución de la identidad narrativa, expresión que tomamos de Shaeffer (1999: 246), la autora concede a Le Mirador una estructura original mediante la cual plasma las identidades de ambas protagonistas. Dos relatos se entrelazan: predomina el elaborado en primera persona, a cargo de una narradora que presta su voz a Irène, nombre

6. "Même si je n'ai pour étayer mes souvenirs improbables que le secours des photos jaunies, de témoignages rares et de documents dérisoires, je n'ai pas d'autre choix qu'évoquer ce que trop longtemps j'ai nommé l'irrévocable: ce qui fut, ce qui s'arrêta, ce qui fut, sans doute, pour aujourd'hui ne plus être, mais ce qui fut aussi pour que je sois encore" (Gille, 2000: 29-30). Gille retoma la obra autobiográfica $W$ ou le souvenir d'enfance (Perec, 1975: 17-18). 
que se consigna como epígrafe introductorio. Dicho apartado se divide en dos grandes bloques: el inicial, fechado en 1929, se extiende durante ocho capítulos mientras que el segundo, cuya referencia cronológica se sitúa en junio de 1942, añade cuatro capítulos más. Lejos de ser fortuitas, las fechas corresponden a momentos trascendentales en la existencia de la madre personaje: la primera, de importantes repercusiones en la vida privada y profesional de Némirovsky, coincide con el año del nacimiento de su hija mayor Denise y la publicación de David Golder. Se trata ésta de la novela que la lanzó a la fama y que aseguró su entrada en el escenario literario de la mano de su editor Grasset quien se encargó de diseñar una campaña publicitaria excepcional (Weiss, 2010: 75-79). En cuanto a la segunda fecha, aunque abarque un periodo más reducido, resulta muy significativo al referirse a la época en que por el curso de los acontecimientos, la escritora se ve forzada a abandonar un París sumido en la violencia antisemita y a refugiarse en la pequeña población de Issy-l'Évêque. La narradora focaliza su punto de mira en el último mes y medio previo a la deportación de Irène. La Némirovsky de papel se concentra entonces en la escritura de Suite française, donde hace gala de su clarividencia -aunque tardía y sin felices consecuencias, sobre el oscuro futuro que apunta ya en el horizonte europeo. A partir de esas fechas, el relato pasa revista a toda una vida de manera que, pese a la progresión aparentemente lineal, los recuerdos derivan en flash-backs. Se origina un continuo vaivén entre el presente y el pasado. El hilo temporal del relato no coincide con el de la Historia, aunque conduce al lector a reflexionar sobre los principales acontecimientos de la primera mitad del siglo. La heterogeneidad temporal del discurso narrativo permite a la autora concentrarse en aquellos acontecimientos más relevantes para la vida de su protagonista. La infancia y la adolescencia gozan de un cierto privilegio frente a la década de los años treinta. La amplitud concedida al mes y medio previo a la muerte de Irène acentúa el efecto dramático del relato: el tiempo se lentifica, su transcurso pesa como una losa para traducir la angustia vital de Némirovsky. Dicha estructura responde a la voluntad de Gille de reproducir paso a paso el proceso de constitución de una identidad, de comprender las circunstancias que la motivan. Solo así puede valorarse la trascendencia de las constantes desavenencias con la madre, la influencia de las niñeras encargadas de su formación, el apego a su tía materna, la adoración a un padre demasiado ocupado en colmar las necesidades materiales de su familia, la rutina bañada por el lujo y 
la ostentación que sintetizan la infancia evocada. La subjetividad que conlleva lo privado se compensa con ese trasfondo histórico. Gille pone particular empeño en mostrar hasta qué punto el racismo manifiestamente ostensible en la segunda parte de la obra se encuentra latente en las etapas previas. De este modo, cuando el lector toma cierta perspectiva y valora en su conjunto la trayectoria de Némirovsky, con su persistente ir y venir, es fácil identificar en ella el reflejo de la leyenda del judío errante, lo cual imprime a su vida un acento marcadamente trágico. Por otro lado, al recurrir a la "narración natural" (Schaeffer, 1999: 246), Gille contribuye a la verosimilitud de la ficción: los hechos relatados se presentan como transposición de la realidad. Dicha similitud se percibe, por ejemplo, entre las declaraciones de Gille respecto al comportamiento de su abuela:

L'appartement de nos parents avait été pillé. Et quand Julie nous a conduites chez notre grand-mère -la mère de ma mère, qui est décrite comme un monstre dans Le Bal et dans David Golder-, celle-ci nous a renvoyées en disant: "Il y a des sanatoriums pour les enfants pauvres" (Gille, 2000: 421).

Y su reflejo en la diégesis:

L'huis s'entrouvre. "Madame Némirovsky, dit-elle [Julie], voici vos petites-filles qui ont survécu à la guerre et que je vous ramène". "Je n'ai pas de petites-filles" grommelle une voix de loup avec un fort accent étranger. "L'aînée a une pleurésie", insiste Julie. "Il y a des sanatoriums pour les enfants pauvres”, répond le loup (Gille, 2000: 213).

La autora cuenta asimismo con el saber del receptor, capaz de adivinar la amarga ironía del destino. La distancia entre la perspectiva de Gille $-\mathrm{y}$ por añadidura, la del lector- y la de la protagonista ponen de

7. La animalización introduce un guiño a la propia Némirovsky que recurría a la figura del lobo de forma reiterada en sus obras. Se servía de ella para aludir a individuos ávidos de riqueza, como en Le maître des âmes, hasta el punto de constituir el título de su relato Les Chiens et les Loups, donde la novelista resume el sentir expresado en 1938: "mon affaire, peindre les loups! [...] Les loups, c'est mon affaire, c'est mon talent" (Philipponnat \& Lienhardt, 2007: 307). 
relieve la ingenuidad de esa Irène primípara que, por el hecho de haber alumbrado en suelo francés, confía en un cómodo porvenir para su recién nacida:

Au réveil, j'avais une fille. J'ai demandé à Michel de la déclarer sous le nom de Catherine, à cause des Hauts de Hurlevent. Il préfère France. Il dit qu'il veut la nommer ainsi pour qu'elle sache toute de suite ce qu'elle doit à ce pays qui nous a accueillis, qui nous aime et que nous aimons, où elle n'aura jamais besoin de savoir que ses parents sont russes, juifs, où elle ne risquera ni persécutions ni pogromes, ni révolutions, où nos lointaines origines se dissoudront tranquillement dans la douceur de vivre (Gille, 2000: 35).

La anestesia a la que fue sometida Irène durante su parto, un tanto complejo por el hecho de padecer asma, respondía sin lugar a dudas, a criterios médicos. Sin embargo, Gille proporciona a ese detalle un valor simbólico puesto que la llegada del bebé va acompañada de otro "nacimiento" también relevante para su posterior desarrollo intelectual: despierta entonces la conciencia de Irène sobre las implicaciones de su extranjería.

La singularidad de la obra reside en la presencia diferenciada de dos personalidades: cada capítulo de los referidos a Némirovsky se halla precedido de un texto breve relativo a la biografía de la propia Élisabeth. $\mathrm{Su}$ afán didáctico la impulsa a establecer mecanismos para la distinción de ambas protagonistas: a nivel tipográfico los pasajes sobre Gille se transcriben en cursiva; a nivel narrativo la autora habla de sí misma en tercera persona. La distancia que se impone consigo refleja la voluntad de mirarse como Otra, de autoexaminarse. A lo anterior se añade la datación precisa que, a modo de epígrafe, precede cada fragmento y lo sitúa en un tiempo cronológico distinto al que toma cuerpo en los capítulos consagrados a Némirovsky. En una veintena de pasajes Gille revisa su vida casi al completo puesto que examinan el período entre marzo de 1937 y octubre de 1991, momento este último de escritura de la obra. Pero además dichos textos se convierten en "laboratorio de escritura": al narrar las amargas peripecias de su infancia esboza ya su futura novela $U n$ 
paysage de cendres, no sólo por el tema tratado sino por el paralelismo en los episodios que componen ambas tramas. Así sucede, por ejemplo, en lo referente a la búsqueda de los desaparecidos donde se dan concomitancias notables ${ }^{8}$.

Gille establece un diálogo constante entre madre e hija hasta el punto de que ambas concurren en una respectiva evaluación de los peligros que las conciernen. Su aprendizaje en común debuta en julio de 1942. Gille se representa entonces como una niña de cinco años que vaga en plena libertad por los campos mientras se produce el arresto de su madre. Su perplejidad, su inocencia infantil justifican su error de apreciación en cuanto a los agentes de policía que se encuentra en la casa. Creyendo que su presencia se debe a alguna de sus travesuras, se queda atónita frente a una madre que no la castiga sino que le ofrece sus consejos antes de partir (Gille, 2000: 86). Corresponde al lector descifrar lo tácito, el verdadero alcance del arresto. Ese mismo tema de falta de madurez se retoma en el capítulo siguiente, centrado esta vez en Irène: con ocho años fue testigo de las consecuencias del asesinato de Stolypine en la Ópera de Kiev. Aunque el suceso se interpreta como un accidente que perturba la rutina cotidiana de la élite rusa absorta en su propio bienestar, la evocación del asesino, un obrero judío de Kiev acusado de haber cometido una muerte ritual, anuncia los pilares de un antisemitismo creciente sobre el que se sustentarán las tesis nazis. La correspondencia de ambos hechos en las vidas de las dos mujeres consigue un efecto de repetición, de acumulación que acentúa el drama al cual se vieron sometidas.

Sin embargo, la conexión entre ambas narradoras atiende, además de a su parentesco, a la huella dispar y a la vez común que la guerra imprime en ellas puesto que las enfrenta a retos similares: "Octobre 1943" describe la huída que Gille y su hermana mayor deben emprender para escapar de la policía alemana. El fragmento subraya la ingenuidad de la menor, ajena al drama de su entorno y que se aferra a la pierna de su protectora Julie.

8. Por tan solo citar un ejemplo, los términos utilizados en Un paysage de cendres para aludir a la búsqueda de deportados: "Les adultes, pour la plupart maigres et mal habillés, tenaient des écriteaux sur lesquels s'étalaient en grosses lettres malhabiles des noms accompagnés de photos d'identité minuscules, indéchiffrables à cinquante centimètres de distance. On comprenait à leurs vêtements fripés, à leurs mines fatiguée, à leur façon de laisser s'incliner vers le sol les hampes artisanales de leurs collages bricolés, qu'ils attendaient depuis bien longtemps...” (Gille, 1998: 95) recuerdan los de Gille cuando relata su propia experiencia: “... l'enfant et sa sœur sont plantées sur un quai de gare. Elles brandissent des écriteaux de carton blanc sur lesquels sont calligraphiés avec soin les noms de leurs parents. Quand la fumée de la locomotive commence à se dissiper, ses lambeaux laissent apparaître, voguant sur des civières, des bras rayés aux mains osseuses..." (Gille, 2000: 245). 
Su postura se corresponde con lo vivido por Irène durante el éxodo ruso, cuando su familia se vio obligada a trasladarse de Petrogrado a Moscú iniciándose así su errancia. La narradora refiere tal vivencia en el capítulo cinco - precediendo al pasaje relativo a la misma Gille- y concluye con una Irène acompañada de su madre, ambas al acecho de un futuro incierto e inseguro. En la mente del lector, por analogía, se tiende a esperar un común desenlace que amalgame a las protagonistas. Para aportar solidez a las correspondencias la obra alude a motivos varios que forjan nexos de unión entre ambas: cuando en su imaginación la pequeña Élisabeth evoca el Titánic para referirse al desmembramiento familiar retoma la famosa catástrofe que acaba de ser rememorada por Némirovsky como elemento de comparación para reflejar las terribles consecuencias del deshielo del río Neva en la rutina de la entonces adolescente; esa rayuela olvidada que la pequeña advierte cuando los policías van a buscarla a la escuela (Gille, 2000: 118) reaparece con términos similares entre los juegos que Némirovksy evoca al referir los gustos de sus hijas durante su estancia en Ivy-l'Évêque (Gille, 2000: 285).

En definitiva, Le Mirador constituye un texto autorreferencial donde la distancia entre lo real y lo imaginario se acorta al igual que se diluyen las fronteras entre los géneros para trascender el simple homenaje a la figura materna. Se aprehende con ello la fragilidad de Némirovsky, que no es otra que la de la propia Gille. Al igual que para Irène escribir Suite française supuso un medio de hacer inteligible, de entrever el triste desenlace que le esperaba, la conversación que la hija establece con su madre adquiere un matiz terapéutico al contrarrestar una amnesia voluntariamente impuesta desde su más pronta juventud ${ }^{9}$.

\section{REFERENCIAS BIBLIOGRÁFICAS}

9. “J'ai bâti un mur très solide et si j’ai réussi à mener une existence relativement équilibrée, avec mon mariage, mes enfants, ma carrière de traductrice et d'éditrice, c'est grâce aux défenses que j'ai construites. Le prix de mon équilibre, c'était le refoulement" (Gille, 2000: 416). 
BACHELARD, G. (1960). Poétique de la rêverie. París: PUF.

BORNAND, M. (2004). Témoignage et fiction. Les récits de rescapés dans la littérature de langue française (1945-2000). Ginebra: Droz.

CORPET, O. (2010). Irène Némirovsky. Un destin en images. París: Denoël.

DIDIER, B. (1976). Le journal intime. París: PUF.

GILLE, É. (1998). Un paysage de cendres. París: Seuil. (2000). Le Mirador. París: Stock (édition originale 1992).

LEJEUNE, Ph. (1975). Le pacte autobiographique. París: Seuil.

MORELLO, N. \& RODGERS, C. (2002). Nouvelles écrivaines, nouvelles voix? Amsterdam: Rodopi.

PEREC, G. (1975). W ou le souvenir d'enfance. París: Denoël.

PHILIPPONNAT, O. \& LIENHARDT, P. (2007). La vie d'Irène Némirovsky. París: Grasset-Denoël.

RYE, G. (2009). Narratives of Mothering: Women's Writing in Contemporary France. Newark: University of Delaware Press.

SCHAEFFER, J.-M. (1999). Pourquoi la fiction? París: Seuil.

TALLANDIER, Fr. (2008). "Qui pleure là? La langue française à son miroir". Synergies Monde 5, 179-182.

Recibido el 30 de mayo de 2017.

Aceptado el 15 de septiembre de 2017. 